\title{
Morfogênese e Acúmulo de Forragem em Pastagem de Cynodon dactylon cv. coastcross em Diferentes Estações de Crescimento ${ }^{1}$
}

\author{
Duarte Vilela², Paulo César de Aguiar Paiva ${ }^{3}$, Josiane Aparecida de Lima4, Rodrigo Carvalho \\ de Cardoso 5
}

\begin{abstract}
RESUMO - O experimento foi realizado para se estimar as características morfogênicas e estruturais e a taxa de acúmulo de matéria seca (MS) de lâminas foliares em uma pastagem de Cynodon dactylon cv. coastcross, manejada em sistema de lotação rotacionada com vacas em lactação. As avaliações foram realizadas na primavera (outubro-novembro), no verão (fevereiro-março) e no outono (maio-junho). $\mathrm{O}$ estudo foi conduzido em delineamento de casualização completa, com seis repetições. Durante o período de descanso do piquete, os perfilhos do capim foram identificados para observações e registros de alongamento, aparecimento e senescência foliares. Foram contados perfilhos em área de $0,09 \mathrm{~m}^{2}$, para estimativa da densidade populacional. A taxa de acúmulo líquido de MS de lâminas foliares/ área foi obtida multiplicando-se o acúmulo de MS/perfilho pelo número de perfilhos/área. A taxa de alongamento foliar foi mais alta no verão, enquanto a taxa de aparecimento foliar e o número de folhas/perfilho foram mais elevados na primavera. O número de perfilhos não variou com a estação, apresentando valor médio de $2.770 / \mathrm{m}^{2}$. A taxa de senescência foi, em média, de $2,44 \mathrm{~mm} /$ dia na primavera, não havendo senescência de folhas durante o verão e o outono. A taxa de acúmulo de MS de lâminas foliares foi mais alta no verão e apresentou estreita relação com a taxa de alongamento e com o tamanho da folha. O uso da taxa de alongamento foliar e da densidade de perfilhos para obtenção das taxas de acúmulo de MS de lâminas foliares/ha superestimou os valores.
\end{abstract}

Palavras-chave: alongamento foliar, matéria seca, perfilho, senescência

\section{Morphogenesis and Accumulation of Forage in Cynodon dactylon c.v. Coastcross Pasture at Different Growing Seasons}

\begin{abstract}
The experiment was conducted to estimate morphogenic and structural characteristics and dry matter accumulation rate of leaf blades in a pasture of Cynodon dactylon cv. coast-cross grass intermittently grazed by lactating cows. The evaluations were performed in Spring (October-November), in Summer (February-March) and in Fall (May-June). The study was conducted observing a completely randomized design. with six replications. Leaf length, appearance and senescence in marked tillers were registered over the rest period of the paddock. Tillers in sampling areas of $0.09 \mathrm{~m}^{2}$ were counted for estimation of the tiller population density. The net DM accumulation rate of leaf blades was obtained by multiplying the dry matter accumulation rate by the number of tillers/area. Leaf elongation rate was higher in the Summer; while leaf appearance rate and the number of leaves/ tiller were higher in Spring. Tiller population did not vary with season, averaging 2,770 tillers $/ \mathrm{m}^{2}$. The senescence rate averaged $2.44 \mathrm{~mm} /$ day in the Spring and no leaf senescence was observed over the Summer and Fall. Dry matter accumulation rate of leaf blades was higher in the Summer and showed a close relationship with leaf elongation rate and leaf size. Leaf blade accumulation rate was overestimated when calculated from leaf elongation rate and tiller density data.
\end{abstract}

Key Words: leaf elongation, dry matter, tiller, senescence

\section{Introdução}

A descrição da pastagem em condição vegetativa pode ser definida pela caracterização e combinação das variáveis morfogênicas, em que as taxas de aparecimento e alongamento foliares e a duração de vida das folhas são as características mais importantes. Essas variáveis apresentam estreita correlação com o rendimento forrageiro e são utilizadas como critério de seleção em trabalhos de melhoramento genético e em estudos que avaliam os efeitos dos fatores de meio sobre a produtividade das gramíneas (Horst et al., 1978; Valle et al., 2004). A condição dos fatores do ambiente, como luz, temperatura, água e nutrientes, e as variáveis morfogênicas das plantas, destacando-se o número e tamanho das folhas e a densidade de perfilhos, determinam as características estruturais do relvado (Minson, 1981).

\footnotetext{
${ }_{1}$ Pesquisa parcialmente financiada com recursos do CNPq

2 Pesquisador da Embrapa Gado de Leite. Rua Eugênio do Nascimento, 610 - Bairro Dom Bosco - 36038-330 - Juiz de Fora, MG. Bolsista nível 1 do CNPq. E.mail: vilela@cnpgl.embrapa.br

3 Professor DZO-UFLA. Cx. Postal 37,37200-000 - Lavras, MG. E.mail: pcapaiva@ufla.br

4 D.Sc. Forragicultura e Pastagem. Bolsista RD CNPq. E.mail: jlima@ufla.br

${ }^{5}$ Aluno do curso de Doutorado DZO/UFLA.
} 
A estrutura da pastagem apresenta alta correlação com o consumo do animal em pastejo, sendo determinante na avaliação do valor nutritivo da pastagem (Stobbs, 1973; Mazzanti et al., 1994). Poucas informações sobre as características morfogênicas e estruturais de gramíneas em condições tropicais estão disponíveis na literatura. As forrageiras do gênero Cynodon reúnem características nutricionais e produtivas que permitem elevadas produções por animal e por área (Vilela \& Alvim, 1996,1998; Alvim et al., 1997, 1999; Vilela et al., 2002, 2003). Daí a importância de se realizar medições detalhadas dos componentes de crescimento da pastagem, a fim de se obter melhoria na eficiência de utilização das pastagens. Realizou-se este trabalho com os objetivos de avaliar o efeito das estações primavera, verão e outono sobre as taxas de alongamento, aparecimento e senescência de folhas e estimar o acúmulo total e a taxa de acúmulo líquido de forragem, em pastagem de capim Cynodon dactylon cv. coastcross sob pastejo em sistema de lotação rotacionada.

\section{Material e Métodos}

O trabalho foi conduzido na Embrapa Gado de Leite, no Município de Coronel Pacheco, Minas Gerais, Brasil. Nesta região, existem dois períodos climáticos bem definidos: período seco (abril-maio e setembro-outubro), caracterizado por temperatura média de $17^{\circ} \mathrm{C}$ e precipitação de $60 \mathrm{~mm} / \mathrm{mês}$, e período das águas (outubro-março), com temperatura média de $24^{\circ} \mathrm{C}$ e precipitação mensal em torno de $230 \mathrm{~mm}$.

A área de capim Cynodon cv. coastcross foi dividida em piquetes de $470 \mathrm{~m}^{2}$ e manejada em pastejo sob lotação rotacionada, utilizando-se vacas Holandesas em lactação (nove animais/piquete e cinco/ha). O manejo consistiu de um dia de ocupação/piquete e de períodos de descanso de 25 e 35 dias, respectivamente, na primavera/verão e no outono/inverno. A área foi fertilizada com $200 \mathrm{~kg}$ de N, $200 \mathrm{~kg}$ de $\mathrm{K}_{2} \mathrm{O}$ e $50 \mathrm{~kg}$ de $\mathrm{P}_{2} \mathrm{O}_{5}$ por hectare/ano, divididos em aplicações bimestrais.

O estudo de morfogênese, conduzido segundo delineamento de casualização completa, com seis repetições, foi realizado durante os meses de outubronovembro (primavera) de 2000, fevereiro-março (verão) e maio-junho (outono) de 2001. Com o objetivo de estimar as taxas de aparecimento, alongamento (Mazzanti et al., 1994) e senescência (Mazzanti \&
Lemaire, 1994) de folhas, foram identificados em três piquetes dois grupos de seis perfilhos, espaçados a $20 \mathrm{~cm}$, em um mesmo alinhamento. Cada repetição foi constituída pelo valor médio dos seis perfilhos de cada alinhamento, totalizando seis repetições (dois grupos de perfilhos/piquete $\mathrm{x}$ três piquetes). Foram feitas observações, a cada três ou quatro dias, das folhas emergentes e de seus comprimentos, assim como da senescência das folhas adultas. As observações e os registros, realizados durante o período de descanso, iniciaram três dias após a saída dos animais do piquete e foram repetidos por um período de 30 dias na primavera, 27 dias no verão e 28 dias no outono.

Amostras de lâminas foliares emergentes e expandidas, após medição de seus comprimentos, foram secas em estufa a $65^{\circ} \mathrm{C}$ e pesadas, para se estabelecer o fator de conversão entre comprimento e peso seco ( $\mathrm{mm}$ de lâmina foliar/perfilho transformado em mg de MS de lâmina foliar/perfilho), conforme Mazzanti et al. (1994). Esse procedimento permitiu estimativas das taxas de crescimento e senescência de folhas por perfilho. Foram contados os perfilhos contidos em uma área de $0,09 \mathrm{~m}^{2}$, três por piquete, para estimativa da densidade populacional por unidade de área. A taxa de acúmulo líquido de MS de lâminas foliares por área foi obtida multiplicando-se o acúmulo de MS/perfilho pelo número de perfilhos/área.

Semanalmente, foram feitas amostragens para se estimar a quantidade de forragem disponível e forragem residual após o pastejo, utilizando-se quadrados de $0,5 \mathrm{~m}$ de lado, lançados ao acaso, três vezes em cada piquete, antes e após o pastejo. Toda a gramínea sob o quadrado foi cortada e pesada, determinando-se o teor de MS e, em seguida, a disponibilidade de MS por área e o resíduo pós-pastejo.

Os dados foram submetidos à análise de variância e as médias, comparadas pelo teste Tukey a $5 \%$.

\section{Resultados e Discussão}

As taxas de alongamento e de aparecimento de folhas variaram $(\mathrm{P}<0,05)$ conforme a estação de crescimento (Tabela 1). Maior taxa de alongamento foi observada no verão, sendo $30 \%$ superior às obtidas nas duas outras estações. Por outro lado, a taxa de aparecimento de folhas, expressa em folhas por dia, foi mais alta na primavera e mais baixa no verão e outono. Enquanto na primavera uma folha apareceu a cada 3,1 dias, no verão e no outono, o intervalo para 
Tabela 1 - Variáveis morfogênicas e estruturais do capim Cynodon dactylon cv. coast-cross, conforme a estação de crescimento

Table 1 - Morphogenic and structural variables of Cynodon dactylon cv. coast-cross grass according to growing season

\begin{tabular}{|c|c|c|c|c|c|c|}
\hline \multirow[b]{3}{*}{$\begin{array}{l}\text { Estação } \\
\text { Season }\end{array}$} & \multicolumn{6}{|c|}{$\begin{array}{l}\text { Variável } \\
\text { Variable }\end{array}$} \\
\hline & \multicolumn{3}{|c|}{$\begin{array}{l}\text { Morfogênica } \\
\text { Morphogenic }\end{array}$} & \multicolumn{3}{|c|}{$\begin{array}{l}\text { Estrutural } \\
\text { Structural }\end{array}$} \\
\hline & $\begin{array}{c}\text { Alongamento } \\
\text { (mm/dia/perfilho) } \\
\text { elongation } \\
\text { (mm/day/tiller) } \\
\end{array}$ & $\begin{array}{c}\text { Aparecimento } \\
\text { (Folhas/dia) } \\
\text { Appearing } \\
\text { (Leaves/day) }\end{array}$ & $\begin{array}{l}\text { Número } \\
\text { Dias/folha } \\
\text { Number } \\
\text { Day/leaves }\end{array}$ & $\begin{array}{l}\text { Número folhas } \\
\text { Number leaves }\end{array}$ & $\begin{array}{c}\text { Tamanho folha } \\
(\mathrm{cm}) \\
\text { Leaf size } \\
(\mathrm{cm})\end{array}$ & $\begin{array}{l}\text { Número de } \\
\text { perfilhos } / \mathrm{m}^{2} \\
\text { Number of } \\
\text { tillers } / \mathrm{m}^{2}\end{array}$ \\
\hline $\begin{array}{l}\text { Primavera } \\
\text { Spring }\end{array}$ & $24,54 \mathrm{~b}$ & $0,33 \mathrm{a}$ & $3,1 \mathrm{~b}$ & $9,3 \mathrm{a}$ & $74,0 \mathrm{~b}$ & $2.428 \mathrm{a}$ \\
\hline $\begin{array}{l}\text { Verão } \\
\text { Summer }\end{array}$ & $31,27 \mathrm{a}$ & $0,27 \mathrm{~b}$ & $3,7 \mathrm{ab}$ & $7,3 \mathrm{~b}$ & $115,0 \mathrm{a}$ & $2.974 \mathrm{a}$ \\
\hline $\begin{array}{l}\text { Outono } \\
\text { Fall }\end{array}$ & $23,43 \mathrm{~b}$ & $0,24 \mathrm{~b}$ & $4,2 \mathrm{a}$ & $6,8 \mathrm{~b}$ & $96,0 \mathrm{a}$ & $3.021 \mathrm{a}$ \\
\hline CV $(\%)$ & 18,10 & 11,20 & 12,0 & 11,4 & 15,4 & 23,0 \\
\hline $\begin{array}{l}\text { Média } \\
\text { Mean }\end{array}$ & 26,20 & 0,28 & 3,6 & 7,9 & 93,0 & 2.770 \\
\hline
\end{tabular}

Médias seguidas de mesma letra, na coluna, não diferem entre si pelo teste Tukey a $5 \%$ de probabilidade.

Mean followed by different in the column differ $(P<.05)$ by Tukey test.

aparecimento de folhas foi de 3,7 e 4,2 dias, respectivamente. Carnevalli \& Da Silva (1999) encontraram tendências semelhantes, com valores de 3,07 dias/ folha em setembro-outubro, 3,6 dias/folha em março e 5,7 dias/folha em maio.

Em geral, as taxas de aparecimento e alongamento de folhas aumentam com a temperatura (Gastal et al., 1992). Por isso, o tamanho final da folha, determinado pela relação taxa de alongamento/taxa de aparecimento, eleva-se com a temperatura. Como reflexo do menor intervalo de tempo para aparecimento de folhas, os perfilhos crescidos na primavera apresentaram maior número de folhas de menor tamanho. Por outro lado, folhas crescidas no verão, sob temperaturas mais elevadas, apresentaram maior tamanho, em decorrência, principalmente, da mais alta taxa de alongamento foliar (Tabela 1).

A duração média de vida das folhas é determinante do equilíbrio entre o fluxo de crescimento e o fluxo de senescência. Não foi observada senescência de folhas durante as estações de verão e outono, indicando que a vida útil das folhas do capim Cynodon durante estas estações de crescimento é superior a 28 dias. $\mathrm{Na}$ primavera, foi observado início de senescência de folhas aos 24 dias, com taxa média de 2,49 mm/dia. $\mathrm{O}$ início de senescência de folhas indica que não há mais acúmulo de MS na pastagem - momento certo para entrada dos animais no piquete.
Os efeitos da idade da planta do coastcross sobre a relação caule:folha e os teores de proteína e fibra dessas partes da planta revelaram que, a partir de 28 dias, à medida que a idade do capim avança, diminui a porcentagem de folhas na planta e aumenta a de caules na base de MS, reduzindo a porcentagem de proteína e elevando o teor de fibra em detergente neutro, tanto nas folhas quanto nos caules. Aos 28 dias de idade, o Cynodon dactylon cv. coastcross apresentou, na matéria seca, $70 \%$ de folhas e apenas $30 \%$ de caules, mas aos 100 dias essa relação se alterou. Sob pastejo, recomenda-se a entrada dos animais na área aos 28 dias de descanso; caso contrário, a forragem não apresentará qualidade para proporcionar boas produções de leite.

$\mathrm{O}$ número de perfilhos não variou $(\mathrm{P}>0,05)$ com as estações de crescimento, apresentando média de 2.770 perfilhos $/ \mathrm{m}^{2}$, inferior à encontrada por Carnevalli \& Da Silva (1999), em coastcross (5.000 perfilhos $/ \mathrm{m}^{2}$ ). Esta diferença pode ser atribuída à mais intensa utilização da pastagem e, conseqüentemente, à menor altura residual do relvado $(5 \mathrm{~cm})$ observada no trabalho desses autores. Por outro lado, neste trabalho, após a saída dos animais dos piquetes, a altura residual foi de $20 \mathrm{~cm}$, o que contribuiu para diminuir a incidência de radiação solar na base dos perfilhos.

O perfilhamento é favorecido, entre outros fatores, pela intensidade de radiação solar que alcança o nível 
do solo. Pastagens submetidas à alta pressão de pastejo caracterizam-se por numerosos e pequenos perfilhos, enquanto a presença de perfilhos grandes e pouco numerosos é característica de pastagens submetidas a pastejo menos intenso (Grant et al., 1988).

O acúmulo total de MS de lâminas foliares foi mais alto $(\mathrm{P}<0,05)$ no verão e mais baixo na primavera (Tabela 2), período que, por sua vez, não diferiu do outono $(\mathrm{P}>0,05)$. Conseqüentemente, a taxa de acúmulo de MS (kg de MS de lâminas foliares/ha/dia) estimada no período de verão foi $35 \%$ superior à da primavera e $41 \%$ à do outono, comportamento explicado pelas melhores condições de crescimento observadas durante o verão (mais alta disponibilidade de água, temperatura e radiação) e que reflete a mais elevada taxa de alongamento foliar, característica morfogênica de alta correlação com o rendimento forrageiro (Horst et al., 1978).

Os resultados obtidos sugerem que as taxas de acúmulo de MS de lâminas foliares, calculadas por meio das características morfogênicas e estruturais da pastagem, foram superestimadas. Deve-se considerar que as taxas de 83,$9 ; 89,5$ e $125,6 \mathrm{~kg}$ de $\mathrm{MS} / \mathrm{ha} / \mathrm{dia}$ (Tabela 2) refletem a produção de lâminas foliares. $\mathrm{Na}$ literatura são encontradas taxas de acúmulo total de MS (colmo + folha) de coastcross, estimadas pelo método de corte, variando de 15,7 a 96,2 $\mathrm{kg}$ de MS/ha/dia (Carnevalli \& Da Silva, 1999; Fagundes et al., 1999).

Tabela 2 - Acúmulo total e taxa de acúmulo de MS de lâminas foliares de capim Cynodon dactylon cv. coast-cross, conforme a estação de crescimento

Table 2 - Total accumulation and DM accumulation rate of leaf blades of Cynodon dactylon cv. coastcross, according to growing season

\begin{tabular}{lcc}
\hline & \multicolumn{2}{c}{$\begin{array}{c}\text { Acúmulo de lâminas } \\
\text { Blade accumulation }\end{array}$} \\
\cline { 2 - 3 } $\begin{array}{l}\text { Estação } \\
\text { Season }\end{array}$ & $\begin{array}{c}\text { Total }(\mathrm{kg} / \mathrm{ha}) \\
\text { Total }(\mathrm{kg} / \mathrm{ha})\end{array}$ & $\begin{array}{c}\text { Diário }(\mathrm{kg} / \mathrm{ha} / \mathrm{dia}) \\
\text { Daily }\end{array}(\mathrm{kg} / \mathrm{ha} /$ day $)$ \\
\hline $\begin{array}{l}\text { Primavera } \\
\text { Spring }\end{array}$ & $2.401 \mathrm{~b}$ & $83,9 \mathrm{~b}$ \\
Verão & $3.396 \mathrm{a}$ & $125,6 \mathrm{a}$ \\
Summer & $2.505 \mathrm{~b}$ & $89,5 \mathrm{~b}$ \\
$\begin{array}{l}\text { Outono } \\
\text { Summer }\end{array}$ & 24,4 & 23,8 \\
CV $(\%)$ & 2.731 & 98,1 \\
Média & & \\
Mean & & \\
\hline
\end{tabular}

Médias seguidas de mesma letra, na coluna, não diferem entre si pelo teste Tukey a $5 \%$ de probabilidade.

Mean followed by different in the column differ $(P<.05)$ by Tukey test.
Logo, pode-se inferir que a produção de leite não seria prejudicada pela disponibilidade de forragem, tanto pela avaliação morfofisiológica (Tabela 2) quanto pelo método de corte (Figura 1).

Em sistemas de exploração de pastagens, médias elevadas de produções de leite por vaca nem sempre são economicamente viáveis. É sustentável, no entanto, trabalhar a estrutura do rebanho (quantidade máxima de animais em lactação), a lotação animal adequada e o bom desempenho reprodutivo, o que pode promover em elevadas produtividades por área, para que o nível ótimo de produção sempre se eqüivalha ao lucro máximo da atividade.

A Figura 1 ilustra a disponibilidade de MS de pastagem por ha, o resíduo pós-pastejo e a diferença de pastejo, em $\mathrm{kg}$ de $\mathrm{MS} / \mathrm{ha}$. A MS disponível durante o ano, estimada pelo método de corte, se manteve acima de $4.987 \mathrm{~kg}$ de MS/ha (agosto) e o maior valor foi de $9.293 \mathrm{~kg}$ de $\mathrm{MS} / \mathrm{ha}$ (abril). A menor disponibilidade de MS da pastagem, aproximadamente $40 \mathrm{~kg}$ de $\mathrm{MS} / \mathrm{vaca} / \mathrm{dia}$ ou $7,2 \mathrm{~kg}$ de $\mathrm{MS} / 100 \mathrm{~kg}$ de peso vivo, está de acordo com o mínimo exigido (NRC, 2001) para não limitar a produção de leite por falta de volumoso (Figura 1).

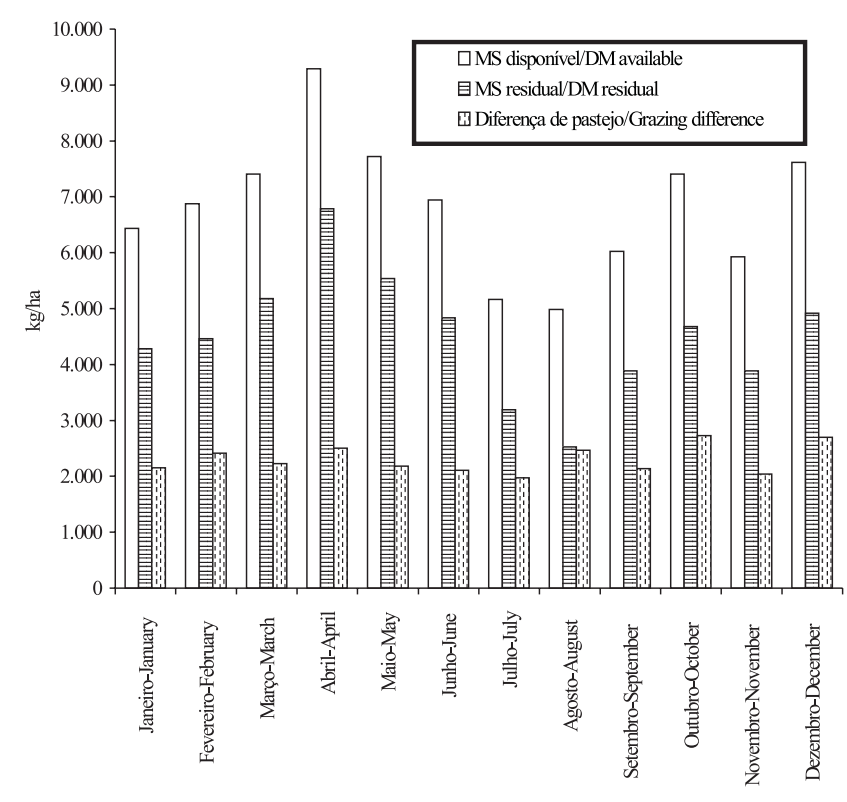

Figura 1 - Disponibilidade e resíduo de MS do capim Cynodon dactylon cv. coastcross sob manejo rotacionado e diferença de pastejo ao longo do ano.

Figure 1 - DM availability and residues of Cynodon dactylon cv. coastcross under rotational management and grazing difference over the year. 
Alvim et al. (1997), utilizando vacas da raça Holandesa em pastagem de coastcross irrigada e fertilizada com $380 \mathrm{~kg}$ de nitrogênio/ha/ano, encontraram, nos períodos de chuvas (outubro a abril) e de seca (abril a setembro), disponibilidades médias de MS de 6,7 e 4,5 t/ha, com a forragem residual de 3,7 e 2,7 t/ha, respectivamente. Esse manejo permitiu consumo de MS de 14 a $17 \mathrm{~kg} / \mathrm{vaca} /$ dia e taxa de lotação média de 3 e 6 vacas/ha, respectivamente, com média anual próxima a 5 vacas/ha. Com base nesses dados e comparando-os com os de forragem disponível e resídual obtidos (Figura 1), pode-se inferir que taxas de lotações semelhantes a essas também seriam obtidas neste estudo.

Normalmente, para evitar degradação de pastagem e garantir vigor à rebrota do relvado, é necessário resíduo mínimo pós-pastejo de $2.000 \mathrm{~kg}$ de $\mathrm{MS} /$ ha. Neste experimento, o menor valor foi 2.522 $\mathrm{kg}$ de MS/ha, obtido no mês de agosto (Figura 1). Pelos dados registrados na literatura (Alvim et al., 1997, 1999), em condições semelhantes às deste trabalho, pode-se inferir que o valor encontrado é suficiente para sustentar produções de leite, superiores a $16 \mathrm{~kg} / \mathrm{vaca} /$ dia em pastagem suplementada com quantidade limitada de concentrado (3 kg/vaca/dia).

A diferença de pastejo estável, independentemente da estação do ano (média de $2.303 \mathrm{~kg}$ de MS/ha), indica que houve equilíbrio do sistema e eficiência de utilização da pastagem ou que as vacas exploraram o máximo potencial de consumo de forragens sem efeito substitutivo entre volumoso e concentrado (Figura 1).

Deresz et al. (2002) concluíram que, para se obter produção de 12 a $14 \mathrm{~kg}$ de leite/vaca/dia, com taxa de lotação de 5 a 6 vacas/ha, é necessário que cada vaca tenha disponibilidade diária de capim de 80 a 100 kg de matéria verde ou de 15 a $18 \mathrm{~kg}$ de MS. A disponibilidade excessiva de pasto, ou seja, o subpastejo, pode resultar em menores produções, em decorrência do acúmulo de fibra detergente neutro e da ligeira queda no teor de proteína da forrageira. A pressão excessiva de pastejo (superpastejo) provoca o aparecimento de plantas invasoras no sistema, situação de pastagens degradadas e, conseqüentemente, baixa produtividade animal. O ideal é manter oferta de forragem acima de $4.000 \mathrm{~kg}$ de $\mathrm{MS} / \mathrm{ha}$ ou, no mínimo, $40 \mathrm{~kg}$ de $\mathrm{MS}$ disponível por animal e resíduo pós-pastejo de $2.000 \mathrm{~kg}$ de MS/ha para garantir vigor a rebrota da pastagem após desfolha.
Mott (1960) e Raymond (1964) verificaram que, na pressão de pastejo ótima, tem-se maior produção por área, como conseqüência da melhor utilização da pastagem, entretanto a produção por animal é comprometida. O subpastejo permite maior eficiência alimentar e, portanto, maior produção por animal.

A variação na disponibilidade de forragem ao longo do ano (Figura 1) sugere a possibilidade de algumas regiões do país se especializarem na produção estacional de leite, em virtude da melhor qualidade e da maior disponibilidade de pastagem no período de outubro a maio. Alternativamente, podem conservar o excesso de volumoso produzido nesse período favorável à produção de forragem de boa qualidade.

\section{Conclusões}

A pastagem de Cynodon dactylon cv. coastcross sob lotação rotacionada suportou taxa de lotação média anual equivalente a cinco vacas holandesas por hectare, não sendo observada deficiência quantitativa de forragem para os animais.

A densidade de perfilhos não variou com a estação de crescimento. A taxa de alongamento foliar e o tamanho das folhas foram mais elevados no verão, enquanto a taxa de aparecimento foliar e o número de folhas/perfilho foram mais altos na primavera.

A taxa de acúmulo de MS de lâminas foliares foi mais elevada no verão e indicou estreita relação com a taxa de alongamento e o tamanho da lâmina foliar.

\section{Literatura Citada}

ALVIM, M.J.; VILELA, D.; LOPES, R.S. Efeito de dois níveis de concentrado sobre a produção de leite de vacas da raça Holandesa em pastagem de coast-cross. Revista da Brasileira de Zootecnia, v.26, n.5, p.967-975, 1997.

ALVIM, M.J.; VERNEQUE, R.S.; VILELA, D. et al. Estratégia de fornecimento de concentrado para vacas da raça Holandesa em pastagem de coast-cross. Pesquisa Agropecuária Brasileira, v.34, n.9, p.1711-1720, 1999.

CARNEVALLI, R.A.; da SILVA, S.C. Validação de técnicas experimentais para avaliação de características agronômicas e ecológicas de pastagens de Cynodon dactylon cv. coast-cross-1. Scientia Agricola, v.56, n.2, p.489-499, 1999.

DERESZ, F.; CÓSER, A.C.; MARTINS, C.E. Suplementação econômica de concentrados em pastagem de capim-elefante manejado em pastejo rotativo. In: Encontro de Produtores de Gado Leiteiro F1, 4., 2002, Belo Horizonte.

FAGUNDES, J.L.; da SILVA, S.C.; PEDREIRA, C.G.S. et al. Índice de área foliar, interceptação luminosa e acúmulo de forragem em pastagens de Cynodon sp. sob diferentes inten- 
sidade de pastejo. Scientia Agricola, v.56, n.4, p.1141$1150,1999$.

GASTAL, F.; BÉLANGER, G.; LEMAIRE, G. A model of the leaf extension rate of tall fescue in response to nitrogen and temperature. Annals of Botany, v.70, p.437-442, 1992.

GRANT, S.A.; BARTHRAM, G.T.; TORVELL, L. et al. Comparison of herbage production under continuous stocking and intermittent grazing. Grass and Forage Science, v.43, n.1, p.29-39, 1988.

HORST, G.L.; NELSON, C.J.; ASAY, K.H. Relationship of leaf elongation to forage yield of tall fescue genotypes. Crop Science, v.18, n.5, p.715-719, 1978.

MINSON, D.J. Nutritional difference between tropical and temperate pastures. In: MERLEY, F.H.W. (Ed.) Grazing animals. Amsterdan: Elsevier, 1981. p.143-157.

MAZZANTI, A.; LEMAIRE, G. Effect of nitrogen fertilization on herbage production of tall fescue continuously grazed by sheep. 2. Consumption and herbage efficiency utilization. Grass and Forage Science, v.49, n.3, p.352-359, 1994a.

MAZZANTI, A.; LEMAIRE, G.; GASTAL, F. The effect of nitrogen fertilization upon herbage production of tall fescue sward continuously grazed with sheep. 1. Herbage growth dinamics. Grass and Forage Science, v.49, n.2, p.111-120, 1994.

MOTT, G.O. Grazing pressure and the measurement of pasture production. In: INTERNATIONAL GRASSLAND CONGRESS, 8., 1960, Reading. Proceedings... Reading (s.n.): 1960. p.606-611.

NATIONAL RESERCH COUNCIL - NRC. Nutrients requeriments of the dairy cattle. 7.ed. Washington, D.C.: 2001. 381p.

RAYMOND, W. F. The efficient use of grass. Journal of British Grassland Society, v.19, n.1, p.81-89, 1964.
STOBBS, T.H. The effect of plant structure on the intake of tropical pastures. 2. Differences in sward structure, nutritive value, and bite size of animals grazing Setaria anceps and Chloris gayana at various stages of growth. Australian Journal of Agricultural Research, v.24. p.821-829, 1973.

VALLE, C.B. O papel da biotecnologia de forrageiras para a produção animal. In: REUNIÃO ANUAL DA SOCIEDADE BRASILEIRA DE ZOOTECNIA, 41., 2004, Campo Grande. Anais... Campo Grande: Sociedade Brasileira de Zootecnia, 2004. p.155-164.

VILELA, D.; ALVIM, M.J.; CAMPOS, O.F. et al. Produção de leite de vacas Holandesas em confinamento ou em pastagem de coast-cross. Revista da Sociedade Brasileira de Zootecnia, v.25, n.6, p.1228-1244, 1996.

VILELA, D.; MATOS, L.L.; ALVIM, M.J. et al. Utilização de soja integral tostada na dieta de vacas em lactação, em pastagem de coast-cross (Cynodon dactylon L. Pers.). Revista Brasileira de Zootecnia, v.32, n.5, p.1243-1249, 2003.

VILELA, D.; MATOS, L.L.; ALVIM, M.J. et al. Utilização de gordura protegida durante o terço inicial da lactação de vacas leiteiras, em pastagem de coast-cross. Pesquisa Agropecuária Brasileira, v.37, n.10, p.1503-1509, 2002.

VILELA, D.; ALVIM, M.J. Manejo de pastagens do gênero Cynodon: introdução, caracterização e evolução do uso no Brasil. In: SIMPÓSIO SOBRE MANEJO DA PASTAGEM: MANEJO DE PASTAGEM DE TIFTON, COAST-CROSS E ESTRELA, 1998, Piracicaba. Anais... Piracicaba: Fundação de Estudos Agrários Luiz de Queiroz, 1998. p.23-54.

Recebido em: 12/09/04

Aceito em: 23/02/05 